\title{
GP73 is down-regulated in gastric cancer and associated with tumor differentiation
}

Le-Gao Chen, Hui-Ju Wang, Hai-bo Yao, Tian-Pei Guan, Fang Wu, Xu-Jun He, Ying-Yu Ma, Hou-Quan Tao and Zai-Yuan Ye

\begin{abstract}
Background: Golgi protein 73 (GP73) is a type II Golgi transmembrane protein. It is over-expressed in several cancers, including hepatocellular carcinomas, bile duct carcinomas, lung cancer and prostate cancer. However, there are few reports of GP73 in gastric cancer. This study is aimed at investigating the expression of GP73 and its relationship with clinical pathological characters in gastric cancer.

Methods: GP73 mRNA level was determined by quantitative real-time RT-PCR in 41 pairs of matched gastric tumorous tissues and adjacent non-tumorous mucosal tissues. Western blotting was also performed to detect the GP73 protein level. GP73 protein expression was analyzed by immunohistochemistry in 52 clinically characterized gastric cancer patients and 10 non-tumorous gastric mucosal tissue controls.

Results: The mRNA and protein level of GP73 were significantly down-regulated in gastric tumorous tissues compared with the non-tumorous mucosal tissues. In non-tumorous mucosa, strong diffuse cytoplasmic staining can be seen in cells located at the surface of the glandular and foveolar compartment; while in tumorous tissues, the staining was much weaker or even absent, and mainly in a semi-granular dot-like staining pattern. The expression level of GP73 protein was associated with patients' gender and tumor differentiation.
\end{abstract}

Conclusions: GP73 was normally expressed in non-tumorous gastric mucosa and down-regulated in gastric cancer. Its expression in gastric cancer was correlated with tumor differentiation.

Keywords: GP73, Gastric cancer, Tumor differentiation

\section{Background}

GP73, also known as GOLM1 and GOLPH2, is a type II Golgi transmembrane protein. Structurally, GP73 contains a short $\mathrm{N}$-terminal cytoplasmic domain, a transmembrane domain and a larger luminal C-terminal domain which is composed of a coiled-coil domain and an acid tail. The luminal C-terminal domain is the major function domain of GP73 [1-3]. Mice with a severe truncation of the GP73 $\mathrm{C}$-terminus showed decreased survival and severe epithelial abnormalities of the kidney and the liver [4]. The coiled-coil domain could interact with both precursor and mature sCLU, indicating that GP73 might assist in the post-translational modification, transportation and secretion of sCLU [5]. A proproteinconvertase recognition site $\mathrm{R}^{52} \mathrm{VRR}^{55}$ is located within the C-terminal ectodomain;

\footnotetext{
*Correspondence: zaiyuanye@163.com

Key Laboratory of Gastroenterology of Zhejiang Province, Zhejiang Provincial People's Hospital, Hangzhou 310014, Zhejiang, China
}

PC-mediated cleavage of GP73 transforms the intracellular, Golgi-localized GP73 to a soluble, secretory protein [6]. However, the function of GP73 is still unclear.

GP73 was first identified from a cDNA library derived from the liver of a patient with adult giant-cell hepatitis. It is considered an epithelial cell-specific protein, which is highly expressed in the colon, stomach, prostate and trachea in normal, healthy persons [1]. Liver disease, such as virus infection and cirrhosis, could up-regulate the expression of GP73 in hepatocytes $[1,7,8]$. Recent studies showed that GP73 was over-expressed in several cancers, such as hepatocellular carcinomas [9-11], bile duct carcinomas [11], lung adenocarcinomas [12], prostate cancer $[13,14]$ and seminomas [15]. The expression of GP73 in renal cancer is much more comprehensive. It was reported as down-regulated in the majority of clear cell renal cell cancers (RCCs), but highly-expressed in papillary and chromophobe renal carcinomas [16]. Serum 
GP73 has also been found elevated in hepatocellular carcinomas, bile duct carcinomas and lung adenocarcinomas. It even showed an advantage over $\alpha$-fetoprotein (AFP) for diagnosing early hepatocellular carcinomas $[17,18]$. Also, mRNA expression of GP73 in urine outperformed serum PSA in detecting prostate cancer [13].

Gastric cancer is one of the most common cancers and the second leading cause of cancer-related death worldwide. It has particularly high frequencies in China [19]. Until now, the etiological factors and pathogenesis of gastric cancer have not been fully understood. In this study, we aim to investigate the expression of GP73 and its relationship with clinical pathological characters in gastric cancer by measuring the mRNA and protein expression level of GP73 in gastric tumorous and adjacent non-tumorous mucosal tissues.

\section{Methods}

\section{Materials and patients}

Forty-one pairs of matched gastric tumorous and adjacent non-tumorous mucosal tissues $(>5 \mathrm{~cm}$ from the edge of the tumor)were obtained from patients with primary gastric cancer at the Zhejiang Provincial People's Hospital, China from January 2011 to December 2012. The characteristics of 41 GCsare shown in Table 1. After surgical removal, tissues were frozen immediately in liquid nitrogen and stored at $-80^{\circ} \mathrm{C}$ until use.

Fifty-two paraffin specimens of gastric cancer (GC) tissue (43 males, 9 females) were acquired from Zhejiang Provincial People's Hospital, collected from 2010 to 2011. All cases of gastric cancer were classified according to the WHO classification and staged by means of the pTNM system [20]. The cases consisted of 22 patientsaged $<60$ years, 30 patients aged $\geq 60$ years; 20 patients with the tumor size $<5 \mathrm{~cm}, 32$ patients with the tumor size $\geq 5 \mathrm{~cm}$; 22 patients with moderately differentiated cancer, 30 patients with poorly differentiated cancer; 14 patients with T1 or T2 wall invasion, 38 patients with T3 or T4 wall invasion; 39 patients with lymph node metastasis and 13 patients without lymph node metastasis; 10 patients with distant metastasis and 42 patients with no distant metastasis. The numbers of patients classified by TNM stage were as follows: 18 were at TNM stage I or II; 34 at TNM stage III or IV. The patients were between 32 and 84 years of age, and there was no radiotherapy or chemotherapy prior to the operation. Specimens were fixed by formalin and embedded in paraffin. Tennormal tissue specimens of the stomach from patients without malignant tumors were also obtained by endoscopy as the control group.

All patients provided informed consent for the use of their tissues before surgery. The use of all specimens was approved by the ethics committee of Zhejiang Provincial People's Hospital.
Table 1 Summary of clinicopathologic characteristics of gastric cancer patients

\begin{tabular}{lr}
\hline Clinical parameters & N (\%) \\
\hline Gender & $27(65.9)$ \\
Men & $14(34.1)$ \\
Somen & $23(56.1)$ \\
$<20$ & $18(43.9)$ \\
$\geqq 20$ & \\
Histologic differentiation & \\
Well & $3(7.3)$ \\
Moderately & $17(41.5)$ \\
Poorly & $21(51.2)$ \\
Lymphatic metastasis & \\
No & $11(26.8)$ \\
Yes & $30(73.2)$ \\
Distant metastasis & \\
No & $34(82.9)$ \\
Yes & $7(17.1)$ \\
TNM stage & \\
I & $8(19.5)$ \\
II & $17(41.5)$ \\
III & $10(24.4)$ \\
\hline
\end{tabular}

\section{Quantitative real-time PCR}

qRT-PCR was performed to determine the mRNA level of GP73. Briefly, total RNA was extracted from 40 pairs of matched gastric tumorous and adjacent non-tumorous mucosal tissue specimens, using Trizol (Invitrogen, Camarillo, USA) according to the manufacturer's instructions. cDNA synthesis was carried out with the PrimeScript 1st Strand cDNA Synthesis kit (Takara,DaLian, China), using $1 \mu \mathrm{g}$ of total RNA as the template and OligodT primer under $65^{\circ} \mathrm{C}, 5$ minutes, $42^{\circ} \mathrm{C}, 60$ minutes and $70^{\circ} \mathrm{C}$, 10 minutes of reverse transcription. The resulting cDNA was amplified by qPCR using specific primers with SYBR Premix Ex Taq (Takara, DaLian, China). GAPDH was used as an internal control. Primers for GP73 were 5'-GCAAAGCAACATCTTCCCTA-3' (sense) and 5'CCACAACAAACTTGCCCTC-3' (antisense). Primers for GAPDH were $5^{\prime}$ - TGAAGGTCGGAGTCAACGG$3^{\prime}$ (sense) and 5' - CTGGAAGATGGTGATGGGATT3' (antisense). PCR parameters were as follows: $95^{\circ} \mathrm{C}$ for 5 minutes, followed by 40 cycles of $95^{\circ} \mathrm{C}$ for $10 \mathrm{~s}$, $60^{\circ} \mathrm{C}$ for $20 \mathrm{~s}$ and $72^{\circ} \mathrm{C}$ for $20 \mathrm{~s}$. At the end of the PCR cycles, melting curve analysis was performed. The relative expression of GP73 to GAPDH was calculated using $2^{-\Delta \mathrm{CT}}$ method. 


\section{Western blotting}

Western blotting was performed to investigate GP73 protein level in 5 of 41 pairs of gastric tumorous tissue and adjacent non-tumorous mucosal tissue. Protein was isolated from tissues samples following the RNA extraction. And approximately $30 \mu \mathrm{g}$ of protein was separated on $10 \%$ polyacrylamide gel for two hours. After being transferred to a polyvinylidenedifluoride (PVDF) membrane (GE Healthcare, Fairfield, Connecticut, USA), the samples were probed with primary antibodies against GP73 (1:2,000, Sigma, St. Louis, MO, USA) and $\beta$-actin (1:5,000, Sigma, USA) at $4^{\circ}$ Covernight. After incubating with secondary antibody (1:5,000, CapitalBio, Beijing, China) for $2 \mathrm{~h}$, the membranes were treated with electrochemiluminescence (ECL) reagent (Generay, Shanghai, China) and exposed to autoradiographicfilms.

\section{Immunohistochemical staining}

Immunohistochemical staining was performed by the standard method. Briefly, 52 cases of paraffin-embedded gastric tumors tissues and 10 cases of adjacent nontumorous mucosal tissue controls were cut at $5 \mu \mathrm{m}$ thick and placed on microscopic slides and dried in a $60^{\circ} \mathrm{C}$ oven for $2 \mathrm{~h}$. Then, the sections were de-paraffinized in xylene, rehydrated using a gradient of ethanol concentrations, microwaved in $10 \mathrm{mM}$ citrate buffer for 15 minutes to retrieve antigen, blocked with $3 \%$ hydrogen peroxide for 10 minutes to inhibit endogenous peroxidase activity and incubated with $10 \%$ goat non-immune serum for 20 minutes to reduce background non-specific staining. After that, the sections were incubated with the rabbit anti-GP73 polyclonal antibody (Abcam, Cambridge, UK) (1:100 dilution) at $4^{\circ} \mathrm{C}$ overnight, then incubated with biotin-labeled secondary antibody (Invitrogen,USA) at room temperature for 20 minutes, followed by incubation with HRP-conjugated streptavidin (Invitrogen, USA) at room temperature for 20 minutes. Then, color development was performed with a DAB Substrate Kit (Dako, Carlsbad, USA). Finally, the sections were counterstained with hematoxylin, dehydrated, cleared and mounted.

\section{Evaluation of the immunohistochemicalstainings}

The immunohistochemicalstainings of GP73 were scored by two pathologists independently, based on the intensity and the proportion of positively stained cells. Staining intensity was evaluated with a four-tiered grading system: $0=$ negative, $1=$ weak, $2=$ moderate and $3=$ strong. The percentage of positive cells were scored as follows: 0 for no cell stained, 1 for $1 \%$ to $25 \%$ of cells stained, 2 for 26 to $50 \%$ of cells stained, 3 for 51 to $75 \%$ of cells stained and 4 for more than $75 \%$ of cells stained. Scores for intensity and percentage of positive cells were multiplied. Scores $\leq 3$ was used to define tumors with low GP73 expression and scores $\geq 4$ with high GP73 expression.

\section{Statistical analysis}

Statistical analysis was performed using SPSS software 13.0 (SPSS, Inc., Chicago, IL, USA). The paired-samples t-test was used to analyze the differences of GP73 mRNA expression between tumor and non-tumorous tissues. Chisquare test was applied to assess the statistical significance of the associations between GP73 expression and clinicopathological parameters. $P<0.05$ was considered statistically significant.

\section{Results}

GP73 expression level in gastric tumor and non-tumorous tissue

GP73 mRNA expression was significantly decreased in gastric tumor tissues compared to the adjacent nontumorous tissues $(33 / 41 ; 80.5 \%)$. The expression levels of GP73 relative to GAPDH were much lower in gastric tumorous tissues $(0.259 \pm 0.308)$ than that in non-tumorous mucosal tissues $(0.584 \pm 0.523 ; P<0.01$; Figure 1$)$. Consistent with RT-qPCR, GP73 protein level in gastric tumor samples was significantly lower than that of non-tumorous samples, which was tested by Western blotting (Figure 2).

\section{Correlation between GP73 protein expression and clinicopathologic parameters}

IHC showed that GP73 was highly expressed in adjacent non-tumorous mucosal tissue, but decreased or even absent in gastric tumorous tissues. In non-tumorous mucosa, strong diffuse cytoplasmic staining could be seen in cells located at the surface of the glandular and foveolar compartment (Figure 3A). In tumor tissues, GP73 expression was mainly expressed in a distinct semi-granular dot-like staining pattern (Figure 3B, C). Only a few gastric tumor tissues were found with strong expression of GP73 (Figure 3D).

The correlation between expression of GP73 protein and clinical variables is shown in Table 2. The GP73 expression level was significantly related to the gender of patients $(P=0.027)$ and differentiation $(P=0.049)$. The expression of GP73 in poorly differentiated gastric tumors was much lower than that in moderately differentiated gastric tumors. A total of 21 out of 30 poorly differentiated gastric tumor cases showed low GP73 expression, while in moderately differentiated gastric tumor cases it was only $9 / 22$. Also, the expression of GP73 in male patients was down-regulated more frequently than that in female patients. There was no significant correlation between GP73 expression and other clinicopathologic parameters. 


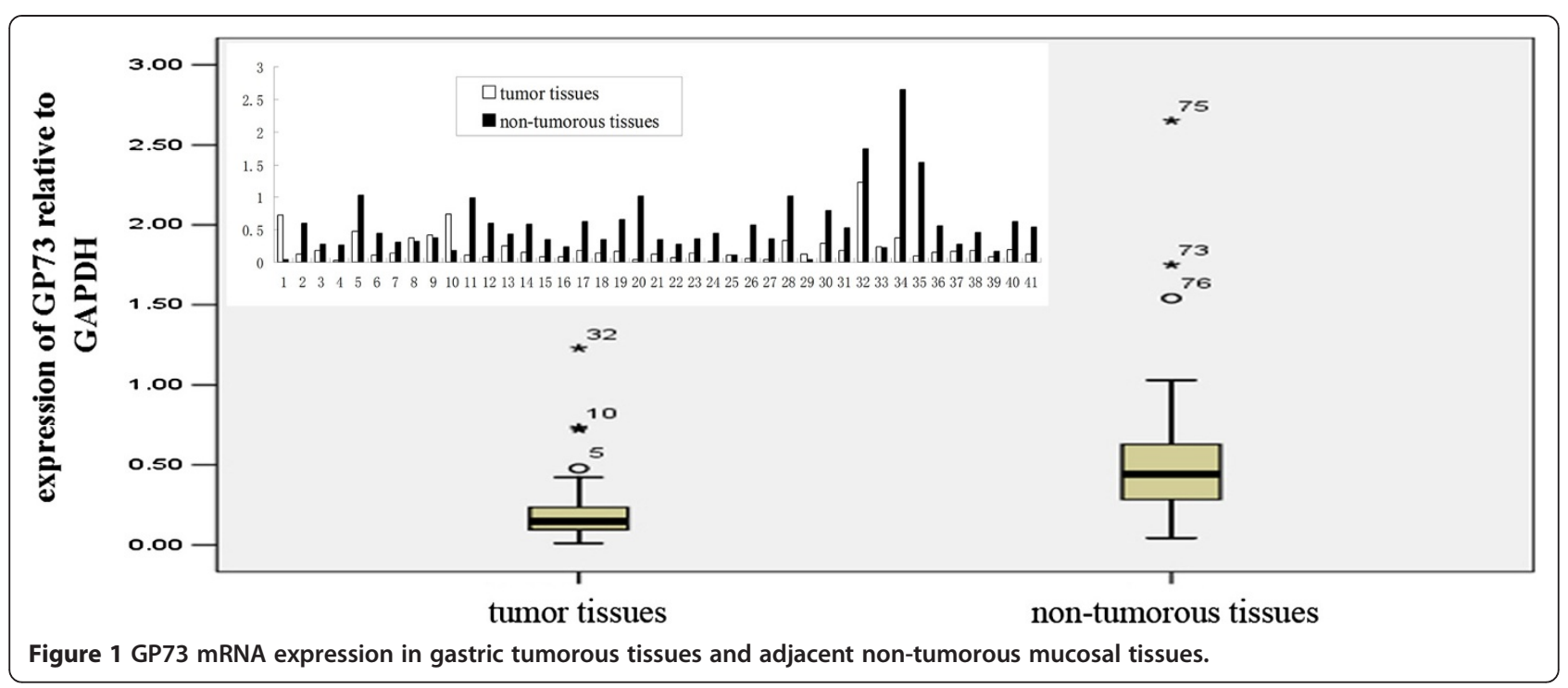

\section{Discussion}

Recently, several studies showed that GP73 is overexpressed in some cancers, including hepatocellular carcinomas, bile duct carcinomas, lung cancer, prostate cancer and seminomas [9-15]. In hepatocellular carcinomas, high-expression of GP73 was associated with tumor size, differentiation, grade and vein invasion [7-9]. In bile duct carcinomas, GP73 expression correlated with patient age and survival [11]. In lung cancer, GP73 expression was associated with tumor histology and patient gender; its expression in adenocarcinoma was significantly higher than in other types of lung cancer [12]. However, no correlation with clinicopathological parameters has been found in prostate cancer and seminomas [13,15]. GP73 also has been found down-regulated in clear cell RCCs, which is the most common histological subtype of renal cell cancer, while its expression in papillary and chromophobe RCC was strong [18]. In the present study, we found that both GP73 mRNA and protein levels were highly expressed in non-tumorous gastric mucosas, which were opposite to most previous studies in other cancers.

The knowledge of GP73's function still remains limited. So far, we know that GP73 is essential for liver and kidney to maintain normal function and appearance. It is also known that GP73 may function in assisting in protein transportation and secretion. One such protein, sCLU, has already been identified. sCLU could prevent apoptosis and is over-expressed in various cancers. GP73 could interact with sCLU through coiled-coil domain and assist transportation and secretion of sCLU, which may explain the association between high expressed GP73 and the aggressive behavior of hepatocellular carcinomas [3]. In hepatocellular carcinoma (HCC), the over-expression of GP73 was not only detected in cancer tissues but also in patients' serum, which indicated the significant increase in GP73 levels would provide a marker for early detection. Some reports even stated that GP73 is a better marker than AFP for diagnosing HCC [10,11,18,21]. However, what is the function of GP73 in stomach and why would it be down-regulated in gastric cancer? This is still unclear. GP73 is an epithelial cell-specific protein and highly expressed in numerous normal human tissues, especially in the colon and stomach. It is also predominately expressed in the small intestine, colon and stomach of mice [22]. Consistent with these studies, we also found that GP73 was highly expressed by cells located 


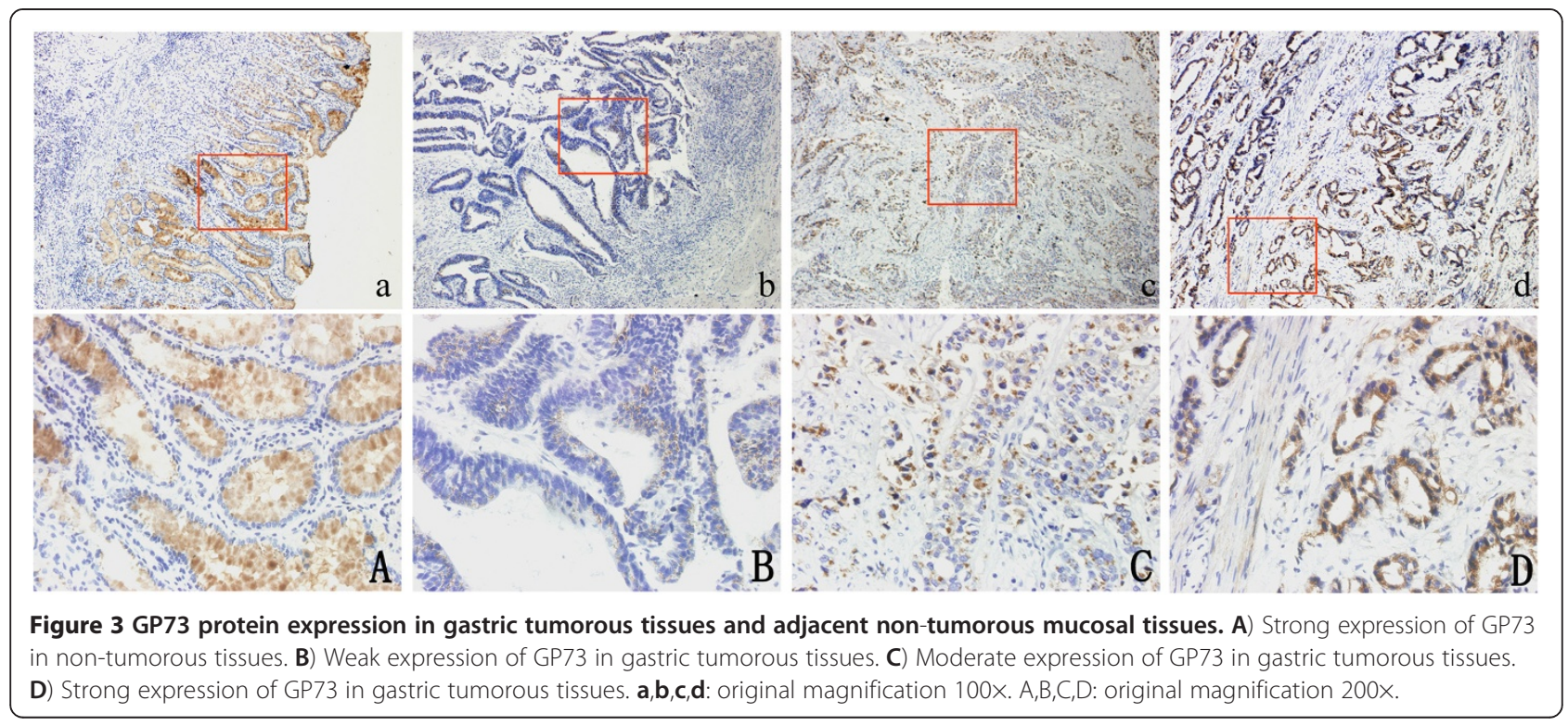

Table 2 Relationship of GP73 expression with pathological parameters of tumor

\begin{tabular}{|c|c|c|c|}
\hline \multirow[t]{2}{*}{ Clinical parameters } & \multicolumn{2}{|c|}{ GOLPH2 } & \multirow[t]{2}{*}{$P$-value } \\
\hline & Low & High & \\
\hline Total number & 30 & 22 & \\
\hline Gender & & & 0.027 \\
\hline Male & 28 & 15 & \\
\hline Female & 2 & 7 & \\
\hline Age (years) & & & 0.456 \\
\hline$<60$ & 12 & 10 & \\
\hline$\geq 60$ & 18 & 12 & \\
\hline Tumor size $\left(\mathrm{cm}^{2}\right)$ & & & 1.000 \\
\hline$<20$ & 14 & 6 & \\
\hline$\geq 20$ & 16 & 16 & \\
\hline Differentiation & & & 0.049 \\
\hline Moderately differentiated & 9 & 13 & \\
\hline Poorly differentiated & 21 & 9 & \\
\hline Stage & & & 0.390 \\
\hline $1+\|$ & 12 & 6 & \\
\hline III+IV & 18 & 16 & \\
\hline Depth of wall invasion & & & 1.000 \\
\hline $\mathrm{T} 1+\mathrm{T} 2$ & 8 & 6 & \\
\hline $\mathrm{T} 3+\mathrm{T} 4$ & 22 & 16 & \\
\hline Lymphatic metastasis & & & 0.757 \\
\hline No & 7 & 6 & \\
\hline Yes & 23 & 16 & \\
\hline Distant metastasis & & & 0.725 \\
\hline No & 25 & 17 & \\
\hline Yes & 5 & 5 & \\
\hline
\end{tabular}

at the surface of the glandular and foveolar compartment of normal human gastric mucosa. Since the highest expression of GP73 is in epithelial cells of digestive organs, it is reasonable to presume that it may play some important, unknown roles in the digestive system.

We also found the expression of GP73 was associated with tumor differentiation. The expression of GP73 in poorly differentiated gastric tumors was much lower than that in moderately differentiated gastric tumors. It was reported that knock-down of GP73 in HepG2.2.15 cells could cause a reduction in the surface area of the Golgi complex. Since the size and development of the Golgi complex are positively correlated with tumor differentiation, some researchers hypothesized that GP73 expression might be associated with maintaining the structural integrity of the Golgi complex during oncogenesis [23,24]. Recent studies demonstrated that loss of GP73 caused up-regulation of WT1, which may promote glomus formation and inhibit pronephric tubule differentiation. It suggested that GP73 plays an important role in pronephros development and differentiation [25]. In hepatocellular carcinoma, GP73 protein was strongly associated with tumor size, vein invasion and tumor differentiation, suggesting GP73 expression is correlated with the aggressive behavior of cancer [10]. Moreover, the expression of GP73 was also associated with patient gender. Male patients showed low GP73 expression more frequently than female patients. A similar phenomenon has also been reported in lung cancer. Female patients had a higher expression of GP73 than male patients [12]. It is also reported that phenotypic changes observed in mice with truncated GP73 C-terminus are genderdependent [4]. One explanation is that GP73 mRNA is regulated by estrogens and calcitriol [26]. Our work 
again confirmed the hypothesis that GP73 expression is under hormonal control.

\section{Conclusion}

In conclusion, we found that both the GP73 mRNA and protein level was significantly down-regulated in gastric tumorous tissues compared to the non-tumorous mucosa, and the expression of GP73 was associated with tumor differentiation and patient gender. Our further work will focus on investigating the function and the regulation mechanism of GP73 in the stomach.

\section{Abbreviations}

AFP: a-fetoprotein; ECL: Electrochemiluminescence; GC: Gastric cancer; GP73: Golgi protein 73; HCC: Hepatocellular carcinoma; PSA: Prostate specific antigen; PVDF: Polyvinylidenedifluoride; RCC: Renal cell cancer.

\section{Competing interests}

The authors declare that they have no competing interests.

\section{Authors' contributions}

LGC and HJW were involved in the design of the study, performed the QRT-PCR, Western bolting and immunohistochemical staining analysis, and drafted the manuscript. ZYY and HQT were involved in the design of the study and supervised the study. HBY, FW and TPG collected data and helped to draft the manuscript. XJH and YYM provided general support and helped to draft the manuscript. All authors read and approved the final manuscript.

\section{Acknowledgments}

This work was supported by Zhejiang Provincial Program for the Cultivation of High-level Innovative Health Talents.

\section{Received: 9 October 2012 Accepted: 9 May 2013}

Published: 7 June 2013

\section{References}

1. Kladney RD, Bulla GA, Guo L, Mason AL, Tollefson AE, Simon DJ, Koutoubi Z, Fimmel CJ: GP73, a novel Golgi-localized protein upregulated by viral infection. Gene 2000, 249:53-65.

2. Kim HJ, Lv D, Peng T, Ma X, Zhang Y: Golgi phosphoprotein 2 in physiology and in diseases. Cell Biosci 2012, 2:31.

3. Puri S, Bachert C, Fimmel CJ, Linstedt AD: Cycling of early Golgi proteins via the cell surface and endosomes upon lumenal $\mathrm{pH}$ disruption. Traffic 2002, 3:641-653.

4. Wright LM, Yong S, Picken MM, Rockey D, Fimmel CJ: Decreased survival and hepato-renal pathology in mice with C-terminally truncated GP73 (GOLPH2). Int I ClinExp Pathol 2009, 2:34-47.

5. Zhou Y, Li L, Hu L, Peng T: Golgi phosphoprotein 2 (GP73/GP73/GOLM1) interacts with secretory clusterin. Mol Biol Rep 2011, 38:1457-1462.

6. Bachert C, Fimmel C, Linstedt AD: Endosomal trafficking and proproteinconvertase cleavage of cis Golgi protein GP73 produces marker for hepatocellular carcinoma. Traffic 2007, 8:1415-1423.

7. Kladney RD, Cui X, Bulla GA, Brunt EM, Fimmel CJ: Expression of GP73, a resident Golgi membrane protein, in viral and nonviral liver disease. Hepatology 2002, 35:1431-1440.

8. Kladney RD, Tollefson AE, Wold WS, Fimmel CJ: Upregulation of the Golgi protein GP73 by adenovirus infection requires the E1A CtBP interaction domain. Virology 2002, 301:236-246.

9. Hu JS, Wu DW, Liang S, Miao XY: GP73, a resident Golgi glycoprotein, is sensibility and specificity for hepatocellular carcinoma of diagnosis in a hepatitis B-endemic Asian population. Med Oncol 2010, 27:339-345.

10. Sun Y, Yang H, Mao Y, Xu H, Zhang J, Li G, Lu X, Sang X, Zhao H, Zhong S, Huang J, Zhang $H$ : Increased Golgi protein 73 expression in hepatocellular carcinoma tissue correlates with tumor aggression but not survival. J Gastroenterol Hepatol 2011, 26:1207-1212.

11. Riener MO, Stenner F, Liewen H, Soll C, Breitenstein S, Pestalozzi BC, Samaras $P$, Probst-Hensch N, Hellerbrand C, Müllhaupt B, Clavien PA, Bahra M, Neuhaus P,
Wild P, Fritzsche F, Moch H, Jochum W, Kristiansen G: Golgi phosphoprotein 2 (GP73) expression in liver tumors and its value as a serum marker in hepatocellular carcinomas. Hepatology 2009, 49:1602-1609.

12. Zhang F, Gu Y, Li X, Wang W, He J, Peng T: Up-regulated Golgi phosphoprotein 2 (GP73) expression in lung adenocarcinoma tissue. Clin Biochem 2010, 43:983-991.

13. Kristiansen G, Fritzsche FR, Wassermann K, Jäger C, Tölls A, Lein M, Stephan C, Jung K, Pilarsky C, Dietel M, Moch H: GP73 protein expression as a novel tissue biomarker for prostate cancer: implications for tissue-based diagnostics. Br J Cancer 2008, 99:939-948.

14. Varambally S, Laxman B, Mehra R, Cao Q, Dhanasekaran SM, Tomlins SA, Granger J, Vellaichamy A, Sreekumar A, Yu J, Gu W, Shen R, Ghosh D, Wright LM, Kladney RD, Kuefer R, Rubin MA, Fimmel CJ, Chinnaiyan AM: Golgi protein GOLM1 is a tissue and urine biomarker of prostate cancer. Neoplasia 2008, 10:1285-1294.

15. Fritzsche FR, Kristiansen G, Riener MO, Dietel M, Oelrich B: GOLPH2 expression may serve as diagnostic marker in seminomas. BMC Urol 2010, 10:4.

16. Fritzsche FR, Riener MO, Dietel M, Moch H, Jung K, Kristiansen G: GP73 expression in renal cell cancer. BMC Urol 2008, 8:15.

17. Marrero JA, Romano PR, Nikolaeva O, Steel L, Mehta A, Fimmel CJ, Comunale MA, D'Amelio A, Lok AS, Block TM: GP73, a resident Golgi glycoprotein, is a novel serum marker for hepatocellular carcinoma. J Hepatol 2005, 43:1007-1012

18. Zhou Y, Yin X, Ying J, Zhang B: Golgi protein 73 versus alpha-fetoprotein as a biomarker for hepatocellular carcinoma: a diagnostic meta-analysis. BMC Cancer 2012, 12:17.

19. Ling Y: Incidence and mortality of gastric cancer in China. World J Gastroenterol 2006, 12:17-20.

20. Wittekind C, Compton CC, Greene FL, Sobin LH: TNM residual tumor classification revisited. Cancer 2002, 94:2511-2516.

21. Ba MC, Long H, Tang YQ, Cui SZ: GP73 expression and its significance in the diagnosis of hepatocellular carcinoma: a review. Int J Clin Exp Pathol 2012, 5:874-881

22. Block TM, Comunale MA, Lowman M, Steel LF, Romano PR, Fimmel C, Tennant BC, London WT, Evans AA, Blumberg BS, Dwek RA, Mattu TS, Mehta AS: Use of targeted glycoproteomics to identify serum glycoproteins that correlate with liver cancer in woodchucks and humans. Proc Natl Acad Sci USA 2005, 102:779-784.

23. Iftikhar R, Kladney RD, Havlioglu N, Schmitt-Gräff A, Gusmirovic I, Solomon $\mathrm{H}$, Luxon BA, Bacon BR, Fimmel CJ: Disease- and cell-specific expression of GP73 in human liver disease. Am J Gastroenterol 2004, 99:1087-1095.

24. Wright LM, Huster D, Lutsenko S, Wrba F, Ferenci P, Fimmel CJ: Hepatocyte GP73 expression in Wilson disease. J Hepatol 2009, 51:557-564.

25. Li L, Wen L, Gong Y, Mei G, Liu J, Chen Y, Peng T: Xenopus as a model system for the study of GOLPH2/GP73 function: Xenopus GOLPH2 is required for pronephros development. PLoS One 2012, 7:e38939.

26. Moggs JG, Ashby J, Tinwell H, Lim FL, Moore DJ, Kimber I, Orphanides G: The need to decide if all estrogens are intrinsically similar. Environ Health Perspect 2004, 112:1137-1142.

doi:10.1186/1477-7819-11-132

Cite this article as: Chen et al:: GP73 is down-regulated in gastric cancer and associated with tumor differentiation. World Journal of Surgical Oncology 2013 11:132.

\section{Submit your next manuscript to BioMed Central and take full advantage of:}

- Convenient online submission

- Thorough peer review

- No space constraints or color figure charges

- Immediate publication on acceptance

- Inclusion in PubMed, CAS, Scopus and Google Scholar

- Research which is freely available for redistribution 